Jerry Shereshewsky

has more than 30 years' experience in advertising and product marketing working at Young \& Rubicam,

Wunderman, Burson

Marsteller, BMG Music,

Yoyodyne and now Yahoo!. He developed an expertise in direct marketing in the early 1980s, bringing Gevalia to the USA for General Food (now Kraft).

Keywords: permission marketing, direct marketing, online marketing, spam
Jerry Shereshewsky Agency Director

Yahoo

111 West 40th St.

New York, NY 10018

Tel: 212-381-6829

E-mail: jhs@yahoo-inc.com

\section{Permission versus permissive marketing}

\author{
Jerry Shereshewsky \\ Received (in revised form): 9 May 2001
}

\begin{abstract}
About four years ago Seth Godin ${ }^{1}$ coined the phrase 'permission marketing'. It was an attempt to provide a handy catchphrase to describe a new marketing ideology, and resulted in a best-selling book and a new career for Seth as a public speaker. Unfortunately most of the folks who read the book and heard the speeches just got it wrong. The ideology of 'permission' devolved into the practice of 'permissiveness'.

The time has come to try to set the record straight. This paper is yet another attempt to explain permission fully, especially in contrast to the egregious nature of what many have tried to pass off as permission marketing.
\end{abstract}

\section{Permissive marketing}

Since we have started with this bogeyman called 'permissive marketing', perhaps it should be described to explain why it gets so easily confused with 'permission'.

Permissive marketing, like permissiveness in general, is a disregard for the feelings and sensitivities of others, and is a focus on the immediate needs and self-gratification urgencies of the marketer. It presumes a great deal. Classic examples are all the so-called 'permission-based' lists being offered for rental or purchase. The transference of permission is classic permissiveness.

These lists, chock full of names and e-mail addresses of people who somewhere and somehow granted permission to someone for something, are foisted on the marketplace as carrying a higher level of value (not to mention price tag) than mere randomly generated addresses.

Not only are these lists misnamed, but the use to which they are placed is about as far from permission marketing as one can get. The main use is something that most of us would call spam. Working on the principle that even a blind squirrel finds an acorn occasionally, the permissive marketer sends out millions of e-mails at virtually no cost to himself and, because you can indeed fool some of the people some of the time, actually gets back responses and purchases.

This apparent success only goads the permissive marketer into doing it again and again. And he is instantly copied by legions of even less intelligent folks who clog the channel and cause anger and anxiety to proliferate, bringing the threat of governmental intervention ever closer.

At the end of the day, permissive marketing is nothing new, just old, sour wine poured into a new bottle with a fancy label. 
Assumptions

\section{Permission marketing}

Permission marketing is a way of doing things - a process. It is premised on several key assumptions.

- The more you know about the prospect the greater the likelihood that you can find points of interconnectivity between your product/service and that prospect.

- Prospects are loath to tell strangers too much about themselves.

- Friends are willing to tell friends about themselves.

- People prefer to buy things, especially expensive or risk-laden things, from friends rather than strangers.

- Friendship takes time to develop.

- You cannot sell something to someone who does not want to be sold.

These six points are the key building blocks of permission marketing.

\section{Acquiring knowledge}

The first point - knowledge the opportunity to make interconnections - is fundamental.

When I was a college student I earned my tuition by selling cars. We sold sports cars, in fact. Mostly English. And in 1968 that meant twoseaters with mediocre heating systems and even more mediocre electrics. People who owned Triumphs and MGs were a unique and hardy breed. But warm weather and a lack of first-hand experience caused many less hardy types to come and gawk and kick tyres... and even occasionally buy.

A critical decision for a car salesman is to determine the likelihood that any particular prospect will or will not become a buyer. Wasting time on a tyre kicker means that a real buyer may get frustrated and leave for the dealer down the block. So we were trained to look for cues to future behaviour. Wedding ring? Baby seat in the back? Balding pate combed in such a way as ultimately to make driving with the top down impossible? There are a myriad of clues and cues that we look for; each designed to help us not only evaluate the potential of this buyer for that car, but also to help point us to the car that is most likely to satisfy their needs.

Sometimes you can intuit these things. But most of the time it is far better to ask real and clear questions. Will this be your only vehicle? Do you have kids? How much do you need to carry in the boot? Can your partner drive a car with manual transmission? Questions like that help shape the discussion. In fact, they often help the prospect frame their own decision-making process; the right questions get you relevant answers.

This same process can easily be transferred to the world of online direct marketing. Ask the right questions and make sure that the prospect understands the questions, why they are being asked and why answering them will be a benefit to them, and you will get excellent responses. Importantly, someone who is not willing to give you that information is not sufficiently advanced in the decision-making process actually to be considered a real prospect.

This suggests that the process of accumulating information (note, it is a 
process rather than an event) is ongoing and begins literally at the first moment of contact. Much of the necessary information can be inferred. Where did the prospect come from? What do we already know about that prospect from timing, context, source, etc? One rule of thumb on acquiring incremental information (data) is to ask this simple question: 'Is this something I really need now, for this stage of our relationship?' If it is you should be able to explain the need in terms of the self-interest of the prospect (for instance, your zip code will allow us to point you to the representative closest to you). And remember, because this is a process the longer the prospect stays engaged the likelier they are to begin to trust you and give you ever more intimate data. Asking for really important stuff on the first meeting is a bit like proposing on the first date.

The exchange of information is like a dance. It is best done in tandem. They give, you get. You give, they get. The very act of giving on the part of the prospect raises the value of that prospect. Their overall score gets higher and you should and will be willing to invest more and more time and effort to bring this one to a close. To turn a prospect into a buyer and into a customer.

\section{The buyer}

It is worth digressing at this point to discuss the actual nature of a buyer. A buyer is someone who is:

— ready to buy what you are selling

— willing to buy it from you

- able to complete the transaction.

All three conditions must be present for a transaction actually to take place. If the answer any one of them is not 'yes' then the individual is merely a prospect and not yet a buyer. And most of the time, especially early in the process, that is exactly what they are: prospects.

\section{Scalability}

This is also why actually making a sale is so difficult in media. We hear very few 'yeses' and a ton of 'no response'. In traditional media we are forced, by the non-scalability of media, to treat no response as 'no'. But in general, no response merely means 'not now' or 'not this one' or 'I'm busy just now'. But here is where online marketing diverges from the traditional print, broadcast or direct mail. Online media - with

\section{Online marketing diverges from print} permission - scales. And this changes the entire equation... radically.

Permission marketers understand this. Permissive marketers do not.

Scalability is one of those terms that comes from the software business model. You invest a ton in developing the product, and then the manufacturing costs are so low that each incremental unit sold after the initial investment is recouped is virtually pure profit. This also applies to new media.

In all traditional media reach, the process of initially reaching a person has a cost $(x)$. Each incremental time you wish to speak with that individual the cost $(x)$ is repeated. The tenth television commercial 


\section{Rapport}

viewed by a prospect costs as much to deliver as the first. The 18th piece of direct mail has essentially the same printing, postage and lettershop costs as the first. Etcetera. In other words, repeat exposure does not scale... it does not get less expensive to repeat a message or conduct a dialogue.

This has been the advertising paradigm for more than 100 years. But the Internet changes this paradigm, dramatically.

Online, the cost of initial reach is fundamentally the same as it is offline $(x)$. But this is where the magic of permission comes in. If, by some miracle, the marketer can persuade the prospect to raise a hand, to self-identify and overtly grant permission for recontact, the cost of that recontact can be fundamentally zero! In other words, once a prospect has opened the door to dialogue the cost of marketing declines precipitously. This is why permission marketers work so hard to get a prospect to selfidentify.

\section{Making friends}

So how do they do it? They go back to the six building blocks of permission. They recognise that people buy from friends and give information to friends. And they recognise that friendship takes time to develop. So, instead of asking for the order, they go slowly (after all, the cost of going slow is nominal). They seek to establish rapport. Contrast this is the permissive marketer, who asks for the order on the first meeting.

Imagine walking into a bar and asking the first person you met to marry you. My guess is that you get, at best, a strange look and a turned head. Maybe you even get a solid 'no'. So you walk to the next person, and then the next. After completely canvassing everyone in the bar you are still unlikely to be married.

But imagine, instead, that you went back to that same bar, in fact to those same people, and, rather than asking for a high-risk decision like a marriage, you merely suggested having a cup of coffee together on the following afternoon in a well-lit public place. You would, one could wager, be hundreds of times more likely actually to have a second opportunity with those people. You would have dates galore, and from those dates you (and your date) could slowly and carefully examine the pros and cons of marriage with each other.

This metaphor is not at all silly. Just as we tend to marry only a limited number of people (usually one at a time), so brands and companies tend to do business with only a limited number of people. And the more expensive or risk-laden the product or service the more limited the market. So it makes only good sense to consider the appropriateness of dating prospects before popping the question. The better the courtship and the more explicit the mutual understanding, the greater the likelihood of a long-term relationship. It is rare for a 'slam-bam-thank-you-maam' affair to result in a long-term marriage. And, especially in high-price or high-risk categories, long-term marriages are exactly what both parties want. The cost of a sale is way too high for the seller and the cost of buying the wrong product or service is way too high for the buyer. 
This seems to be more than obvious. So why is everyone not a permission marketer and why are there so many permissive marketers?

Permissiveness, as we have seen, is easy. You simply take what you always did and do it again and again. And, as was pointed out earlier, because of the squirrel/acorn principle, such marketers can even make money.

Permission marketing is significantly harder. Because it is a process it takes place over time. And because it is a dialogue the 'script' is significantly more complex. Contrast the ease of writing a headline with the difficulty of writing a short story or a screenplay. The headline need only be impactful (not to diminish the difficulty of writing impactful and persuasive headlines), while the longer, more complex pieces require dramatic builds, inner consistency and a denouement. We remember the great playwrights and novelists, while the copywriters remain largely anonymous.

\section{Customer relationship marketing}

Over the last few years a new discipline has emerged in the world of marketing, CRM, or customer relationship marketing. CRM is a process that focuses on the centrality of the customer. It seeks to know the customer, to recognise the customer when and wherever encountered and to treat that customer uniquely; with product offers and service appropriate to a strategic role assigned to that particular individual.

CRM is hard to implement. It is hard to recognise the customer through the mediated haze; when they call in to the phone centre they do not identify themselves immediately. We have a really difficult time addressing them individually in mass media. And when we have sell from both bricks and clicks it becomes really hard to know them.

But today CRM is where the money is. People recognise the value of the customer relationship and are pouring vast sums into the development and implementation of CRM systems.

\section{Prospect relationship marketing}

Permission marketing is PRM: prospect relationship marketing. Interestingly enough, PRM is significantly easier to do than CRM, and much less expensive. Yet, while CRM is entering adolescence, PRM is in its infancy - in fact the concept does not even really have this name yet... but it will.

The reasons for the slower development of PRM are apparent enough. A customer is a known quantity. A customer has immediate proven worth. The cost of prospecting or replacement is known and understood. The prospect, on the other hand, is still an unknown... a potential. And, historically, businesses (like the rest of us) have always preferred to invest in sure things.

Further, the development of CRM has been spurred by the notoriously low levels of customer loyalty that we can observe in the marketplace. Brilliant theorists like Frederick Reichheld ${ }^{2}$ have helped us understand the nature and value of loyalty (and the costs of disloyalty), and helped 


\section{Prospects are potential assets}

\begin{tabular}{|c|c|}
\hline Nurturing customers & Nurturing prospects \\
\hline Understand value & Estimate value \\
\hline Understand needs & Understand needs \\
\hline Know and measure touchpoints & Build information base \\
\hline Measure impact & Measure progress \\
\hline Reap long-term business & Turn prospect into customer \\
\hline
\end{tabular}

Figure 1: Nurturing relationships

show it to be very much a two-way street. To get loyal behaviour we must behave loyally towards our customers.

This makes totally good sense. And an increasing number of companies are actually beginning to practise customer loyalty. They are going way beyond so-called loyalty programmes (a total misnomer) by really understanding the needs and expressed (and unexpressed) desires of the customer and serving them. They are learning to treat customers for what they are: valuable assets. What an astounding idea!

But if customers are valuable assets, what are prospects? Prospects are potential assets, to be treated with as much dignity and respect as possible if we actually intend that they become customers. What does that mean?

The nature of PRM is fundamentally similar to CRM, only vastly simpler. Yet, as we have said, few practise it. PRM is permission marketing. And the reason it is still in its infancy is that most marketers today are still permissive.

\section{The desire to buy}

It has been argued that the key to permission marketing is persuading the prospect to enter into a dialogue and we have discussed the nature of that first encounter. But why should a person, bombarded by thousands of commercial messages a day, willingly enter into a discussion with someone who obviously wants to sell him something? For one simple reason: it is in his self-interest to do so.

Let us try to understand the consumer (B2C or B2B) and their motivations. They all need to buy stuff. Some actually need or want to buy something very similar to what you make or sell. Your job is to find and persuade them. Theirs is not to make a major mistake.

A friend in the jewellery business put it this way: 'We all know that we will get screwed buying a diamond. ... the question is, how badly?' The process of buying expensive or complex products and services is essentially reduced to minimising the potential screwing. In polite society this is called risk reduction. 
There are three essential kinds of risk:

Risks

- performance risk

- financial risk

- social risk.

We all seek to minimise all of these; either consciously or unconsciously.

Performance risk is connected to the prospect's expectations of the product/service... rather than the normal definition of what the marketer is offering. (Ted Levitt points out the difference between the 'generic product' and the 'expected product'... expected in the customer's mind. ${ }^{3}$ )

Financial risk is based on the fear of losing or wasting money. We do not have a financial risk when buying a pack of chewing gum. But buying the wrong insurance policy, or buying a house in a toxic waste area, or something in between, can be financially disastrous.

Social risk is the least understood of the major risks, but is nonetheless the most profound. For example, I have a brother-in-law who is the authority on audio equipment. Two years ago I purchased a new stereo system for the living room without his consultation. That Christmas he came over, gave the system a cursory once-over and asked 'Who bought this junk?' My standing with his wife and kids immediately plummeted; permanently in terms of audio equipment.

We all seek to mitigate risk. PRM/permission marketing is how marketers help prospects mitigate risk. They first introduce themselves. They establish common grounds of mutual interest and understanding. They slowly insinuate themselves into the thought process. And, eventually, as friends, they know enough about the prospect and the prospect knows enough about them for a deal to be consummated at the appropriate time. Wow!

Using the permission correctly the marketer gradually gets to understand the prospect; fears, wishes, hopes, barriers... all sorts of things that are probably not very apparent at first glance. And it is the careful aggregation of this information into a model of prospect behaviour that determines the pace and direction of the process.

But this process is relatively straightforward - it is premised on the last of the key building blocks: you cannot sell something to someone who does not want to be sold.

Selling something to an unwilling buyer is a waste of time and effort (and probably money). They will probably be dissatisfied, they will not tell their friends, nor will they buy from you again.

This may be OK if you have enormous margins ( the 'made for TV' oneshot comes to mind) but is completely inappropriate in almost all other business situations. But for most companies, most products and most services, it is the ongoing business that counts. And so it is the nature of the relationship rather than the value of the initial transaction that matters most.

\section{Conclusion}

The permissive marketer poisons the well, the permission marketer builds customers. The permissive marketer takes advantage of the aberration of 
a costless e-mail medium, the permission marketer uses the unique qualities of the medium to create meaning. The permissive marketer ignores the future for the near-term hit, the permission marketer only builds for the long term. The permissive marketer is tactical, the permission marketer is strategic.

\section{References}

1. Godin, S. (1999) Permission Marketing, Simon \& Schuster.

2. Reichheld, F. (1996) The Loyalty Effect, Harvard Business School Press.

3. Levitt, T. (1980) 'Marketing success through differentiation — Of anything', Harvard Business Review, 1 January. 